\title{
Organizational Patterns Of Scientific and Technical Libraries: An Examination Of Three Issues
}

Three aspects of the problem of library reorganization are considered with specific reference to scientific and technological libraries: the politics of centralization; the concept of accessibility; and the interaction of science and technology. Although these aspects are central to library reorganization, their impact on the structure of university scientific and technical libraries has yet to be understood in order to provide a rational basis of decision making by university administrators, librarians, and library users.

\section{INTRODUCTION}

$\mathrm{T}_{\mathrm{H}}$ . TION which university libraries have assumed over the years, ostensibly to meet the information needs of their users in the most efficient and effective manner possible within resource limitations, represent a topic of continuing interest to university administrators, librarians, and library users. The Association of Research Libraries (ARL) sponsored study, Problems in University Library Management, summarized some of the basic issues related to the organizational structure of university libraries as follows:

Librarians are caught between conflicting pressures for centralization and decentralization of collections and,

Thomas J. Waldhart is assistant professor, College of Library Science, University of Kentucky, Lexington; LeRoy G. Zweifel is professor, Engineering Sciences Library, University of Wisconsin, Madison. consequently, facilities. University administrators desire to hold duplication of collections and dispersal of services to a minimum. Faculty and graduate students press for decentralized departmental libraries. There appears to be a growing trend toward the establishment of large, decentralized libraries covering several major academic fields, such as the life sciences. The more established trend of constructing separate facilities for undergraduate and graduate students continues.

The issue of centralized versus decentralized facilities poses major management problems for university librarians. In planning new construction and considering changes in existing space utilization, the library must decide whether it is more efficient and effective to decentralize or to centralize operations. Librarians indicate that little data are available to assist them in making such decisions. ${ }^{1}$

Whether librarians, university administrators, or library users are "caught between conflicting pressures for centralization and decentralization" depends 
upon their individual perspectives. Although these groups should participate in decisions relating to the organizational structure of university library systems, they are not equally involved in the making of decisions. In most cases, as university administrators control the resources necessary to accomplish major modifications in library systems, they play the major role in decision making. McAnally and Downs noted the apparently declining influence of university librarians and libraries in terms of their ability to participate in high level decisions. ${ }^{2}$ In actuality, the extent to which university librarians can influence major library or university decisions depends largely on the historical background and present conditions at a given university. If the university librarian has the respect and confidence of the administration and faculty he can be expected to have considerable influence and may even provide leadership. If he lacks this respect and confidence or if major decisions related to the library system have traditionally been made by the faculty and/or the administration, authority and responsibility for decision making may shift from the library environment, with the university librarian primarily engaging in matters of implementation.

Although not explicitly stated in the ARL study, much pressure for decentralization of university library systems originates with the faculties and students of scientific and technical fields; thus, the organizational structure of scientific and technical libraries provides the focus for the following discussion.

The commonly assumed advantages and disadvantages of centralized or decentralized scientific and technical libraries in university environments have been repeatedly discussed in the literature of librarianship. ${ }^{3}$ Suffice it to say that most university library administrators, and students of librarianship in general, oppose forms of subject decen- tralization which extend to the departmental level. They argue that such an organizational pattern: (1) generates numerous problems of communication, control, and coordination; (2) results in rising cost through the duplication of library services, materials, personnel, and records; and (3) encourages, wherever materials are not duplicated, the fragmentation of knowledge and the isolation of scientific and technical fields. The trend at many universities to organize scientific and technical libraries around a number of closely related academic fields (e.g., life sciences, physical sciences, engineering sciences, etc.), may result from: (1) an attempt by university administrators and librarians to realize economies of scale (i.e., cost savings in physical plant and operating expenses due to increased size); (2) recognition of the potential benefits of increased accessibility to users; (3) a compromise between factions favoring greater centralization (e.g., a single scientific and technical library) and those favoring greater decentralization (e.g., departmental libraries); (4) a desire to serve more adequately the information needs of interdisciplinary instructional programs and research; or (5) a combination of the above.

Faculty members of academic departments, in contrast to library administrators, often argue for subject decentralization to the departmental level. They contend that their work (primarily their research activities) requires unlimited access to library materials over time, and in addition that library materials should be physically situated in close proximity to the greatest number of potential users. Particularly with respect to scientific and technical libraries, they maintain these factors should supersede what they view to be the essentially economic arguments of library administrators.

Caught between the persuasive arguments of library administrators on the one hand and those of faculty on the 
other are university administrators, who must allocate university resources among competing demands. As a reorganization of a university library system represents a long-term commitment, decisions made today may severely limit future options. Centralization of library systems almost certainly entails the initial expenditure of substantial sums of money in developing the physical plant to house the consolidated collection and the staff to provide services. Change in general is costly, and in a time of short money lack of adequate financial resources has a strong tendency to reinforce the status quo. Thus, unless university administrators are provided evidence of substantial savings in operating expense or improvement in service, it is unlikely that proposals for major reorganization will receive enthusiastic administrative support.

Although any long-range planning must be partially based on "soft" information (e.g., subjective judgments, projections of student enrollment and university growth, changeable building priorities) decision makers would like to have as much accurate or "hard" information as possible regarding the future consequences of alternative courses of action. Unfortunately, most arguments are based exclusively upon the subjective judgment of individuals possessing a strong bias either for or against centralization.

The profession's inability to accumulate this objective information results from a combination of factors. First, any attempt to evaluate the efficiency, effectiveness, and/or benefits derived from a particular pattern of library organization is at best a costly, time-consuming, and in the end, somewhat subjective process. For instance, Evans and Borko identified a range of criteria which seem to hold some potential for accessing the performance of libraries; included are library coverage, response time, accessibility, cost, use, user satis- faction, and a number of combinations of each. ${ }^{4}$ The selection of evaluative criteria represents a complex process. Although some are relatively easy to use (e.g., library coverage or response time), others are extremely difficult to operationalize (e.g., cost-benefits or user satisfaction). Reducing the performance of an entire library system to a limited number of criteria runs the additional danger of underestimating the complexity of most library systems. The selection of cost, for example, as the major performance criterion would probably be unacceptable to the majority of library users, particularly if the study emphasized system cost over user cost or benefits. $^{5}$

Second, although levels of performance could conceivably be determined for a given pattern of organization, it is unlikely that most library systems could examine the performance of alternative patterns of organization. Such an approach would require either the restructuring of the library system for experimental purposes, or perhaps the development of a complex model for simulating the alternative systems. In either case, excessive cost tends to reduce the viability of such an approach.

Finally, where it is possible to generate reliable information which may support decision making, wide variations in local circumstances restrict its use to a given library system at a particular point in time. Some dangers inherent in evaluating the performance of varying patterns of library organization by comparing different library systems, for instance a centralized system at university $X$ with a decentralized system at university $Y$, have already been discussed in detail by Richmond. ${ }^{6}$

For the immediate future there appears to be little likelihood that university administrators, librarians, or library users will possess the ability to predict accurately the level of benefits to be derived from given patterns of library or- 
ganization; too little is known about the relationship between library organization and system performance. Yet without this knowledge individuals are reduced to relying exclusively on intuition or an appeal to authority to serve as a basis for decision making.

Because of their potential impact, three aspects of the problem of library reorganization which have received little attention will be considered: the politics of centralization; the concept of accessibility; and the interaction of science and technology. These topics will be examined to illustrate their importance to the subject at hand and to indicate specific aspects of the problem which seem to deserve additional study.

\section{Politics of Centralization}

It has been observed that "university professors know more about everything else than they know about themselves and their habitat." 7 Although knowledge of the academic system has increased appreciably over the last five years, information related to the role of the university library in that system -particularly the role of the university librarian in the social structure of the university-remains fragmentary. Two recent exceptions to this generalization are a paper by McAnally and Downs, and an interview with Robert A. Miller, reported by Lyle. ${ }^{8,9}$ Both provide insight into the complex social system of which the university library is an integral part and illustrate the importance of the political realities which directors of university libraries must deal with on a continuing basis. Although the economic aspects of centralization receive emphasis in the literature of librarianship, the political aspects of centralization may really determine negotiations for changing library systems.

In universities with traditional departmental decentralization of scientific and technical libraries, faculties have tended to be reluctant to give up "their" libraries. They cite the need for immediate physical accessibility to library materials. Yet, a more compelling, although unstated, reason may be human resistance to change, and the possible consequent loss of administrative control.

Where departmental libraries exist, faculties tend to retain considerable control over matters of library policy and procedures: library hours, availability of library keys, duplication and selection policies, selection of the departmental librarian, establishment of library services, etc. As expected, preferential treatment is often accorded faculty members and graduate students of the department; library users from other departments on campus frequently find these libraries, and their services, considerably less accessible. With centralization, departmental faculties might lose this control over the operation of the library as well as their preferential treatment.

Centralization confers most responsibility and authority for decision making to the office of the director of the centralized facility, rather than upon the faculties of the individual departments. The librarian, rather than focusing on one department, must balance the needs of several departments; he must balance the needs of undergraduates against those of graduate students and faculty; the needs of research against those of instruction. Specifically, the librarian of a centralized facility must consider the scientific and technical information needs of the total academic community subject to limited resources.

Although general improvement in service to the overall academic community might reduce service to specific departments, centralization has considerable potential for improving library service to individuals throughout the academic community. The availability of increased resources (physical, financial, and human) to centralized systems provides an opportunity to develop library 
services which are generally not available in highly decentralized systems-selective dissemination of information, systematic collection development by subject specialists, increased access to subjects of peripheral interest, improved facilities for study and research, exploitation of nonprint media, and document delivery services. In addition, it provides improved access to library materials for the rapidly growing number of educational and research programs which are inter-, multi-, or transdisciplinary in nature.

Too often, however, promises of improved library service made by librarians are not matched by performance, and most scientists and technologists in university environments are aware of this painful fact. Many faculty members have had an opportunity to make use of the university's central library (which represents, in their minds, an example of centralization). They have observed that the library was often overcrowded, extremely large, difficult to get to and once there, difficult to use, impersonal, possessed of loan policies which were restrictive, and stated by individuals having little appreciation of their particular informational needs. The difference between promised and observed performance sometimes generates a credibility gap of monumental proportions.

The ability of the library administrator, usually the university librarian, to bridge this gap will mainly determine the extent of departmental faculty support, which seems necessary to be effective. Nicholson observed:

Centralization will be successful . . . only if complete agreement is reached by faculty, university and library administration that it is the best way in which the greatest number can be effectively served . . . under reasonable financial expenditures. ${ }^{10}$

Most scientists and technologists are less concerned with how the "greatest number can be effectively served" than they are with how they can be more effectively served. If a library administrator cannot secure the active support of the faculty in such a venture, he must do everything possible to reduce active opposition. One way of measuring faculty reaction to centralization is through faculty response to questions of the following nature:

1. Does the library administrator have an understanding and appreciation of the information needs of scientists and technologists? Has this appreciation been demonstrated by his past interest in, and support of, the development of the scientific and technical libraries on campus?

2. What is his record with regard to library matters of primary concern to the scientific and technical community within the university?

3. Will centralization mean a reduction in library service to me? Can the library administrator be trusted to provide the kinds of services that he promises? Does he have the "power" within the university to deliver on such promises?

4. As the system grows in size and complexity can assurances be given that we will continue to be treated as individuals with individual information needs?

Without a perceived record of sensitivity to departmental needs, the university library administrator will have to provide sufficient guarantees that centralization will, in fact, result in improved library services for scientists and technologists.

Little objective data exists on the role of the university librarian in the social structure of the university. Available information primarily considers the relationship of the director of libraries to the library committee (which may or may not be representative of the facul- 
ty of the university as a whole), library staff, students, and sometimes the university administration. Little is known about the attitudes of departmental faculties, particularly in the sciences and technology, toward the university librarian.

In negotiations on the restructuring of the university library system, the degree of empathy displayed by the participants can be critical in determining a program's success or failure. A brief survey of the backgrounds of the directors of the twenty-five largest university libraries in the United States (and thus those thought most likely to be facing the question of centralization or decentwalization) revealed that none possessed a Ph.D. degree in either the physical sciences, engineering, or the life sciences. In addition, twenty-two of the twentyfive directors possessed backgrounds in the humanities or social sciences. ${ }^{11}$ This considerable divergence in backgrounds might have a substantial impact on these negotiations.

Sound sociological research is essential before an adequate understanding of the role of the university library in the academic community can be realized. This understanding is not only important for decision making, but would also contribute greatly to the establishment of realistic library goals, and expectations of library service, in the academic community.

\section{CONCEPT OF ACCESSIBILITY}

Library administrators tend to be less than sympathetic toward demands of science and technology graduate students and faculty for maximum accessibility (both physical and intellectual), because to increase the user's accessibility almost certainly will result in an increase of operating costs. Library administrators do not have to defend user costs (i.e., the physical, psychological, and economic cost which users incur in interaction with the system) at budget- ary meetings, but they do have to defend library operating costs. An interesting example of the conflict between user cost and system cost is described by Dougherty in an evaluation of a document delivery system at the University of Colorado. ${ }^{12}$ Until university and library administrators recognize that reducing library costs often increases user costs (and indirectly university costs), most university library systems will continue to shift the cost burden to the user.

Nevertheless, university library administrators have the obligation to provide the most effective and efficient library service possible within existing budgetary constraints. No matter how efficient a centralized library may be on the basis of library costs, it cannot be effective unless it is used by those for whom the system was designed. The extent to which a library, or any information system is used, depends in large part upon the extent to which potential users perceive the system as being accessible.

Scientists and technologists frequently have emphasized the importance of having documents immediately accessible throughout the course of their teaching and research. Nevertheless, little is known when a library or information service becomes so inaccessible as to be not used.

Defining accessibility in terms of the economic, psychological, and physical cost associated with using a given communication channel, Allen found that, for the groups of engineers studied, accessibility was a critical variable related to the extent to which a communication channel was used..$^{13}$ Further, he concluded that:

Improving the quality of performance of a particular information service (or system) will not in and of itself, lead to increased use of the service. Before the improved information service can lead to increased performance, it must 
be used: And the only way to increase use is through increased accessibility. ${ }^{14}$

At least three dimensions of accessibility are clearly identifiable: distance, time, and familiarity. With distance, for instance, is a library in a building next door inaccessible? Is one down the block inaccessible? How about one across campus? Although Raffel and Shishko provide a methodology, based on location theory, which may provide library administrators with some guidance in the location of centralized or decentralized library systems, the method provides little hope of resolving the essentially psychological problem related to the point at which distance makes a library inaccessible to the point of nonuse..$^{15}$

Similarly, the amount of time required to retrieve a document may influence a user's perception of accessibility. Are documents located in storage, and which require two days to retrieve, considered inaccessible? Are materials acquired through interlibrary loan, and requiring at least two weeks to retrieve, inaccessible in the eyes of the user? Are materials housed in a centralized library, which require twenty minutes walking time from an individual's office inaccessible?

Allen found that the engineer's perception of accessibility was influenced by past experience. The more familiar an engineer was with a given communication channel the more accessible he perceived it to be. ${ }^{16}$ Thus, if an individual makes use of the university's central library once or twice a year he may perceive that library to be relatively inaccessible as compared with, for instance, a departmental library which he uses twice a day. Many individuals who have used centralized scientific and technical libraries have reported that their experiences have been somewhat unsatisfactory. ${ }^{17}$ Whether this lack of satisfaction is a result of low performance on the part of the library or the user's lack of familiarity with the system is unknown. Obviously, the extent to which time, distance, and familiarity affect an individual's perception of accessibility depend on various conditions: ease of use; motivation of the user; his particular information needs; climatic conditions; the physical condition of the user; and many other factors which are difficult or impossible to anticipate.

Although the concept of accessibility is central to most arguments for the decentralization of university scientific and technical libraries, and is recognized by library administrators as an essential to effective library service, it remains a poorly understood aspect of the communication process. As such, it should be used with caution as a measure of system performance for basing decisions on library organization until a systematic examination can be made.

\section{INTERACTION OF SCIENCE AND TECHNOLOGY}

The extent to which departmental decentralization represents an effective and efficient form of university library organization partially depends on the amount of crossover (i.e., "the degree to which those at one market or point of origin [e.g., academic department] use libraries at more than one location") which exists within the library system. ${ }^{18}$ If crossover is negligible, a strong argument can be made for situating the libraries close to the primary market (e.g., the academic department); if crossover is substantial, libraries should be placed so that they are most convenient to the total user population. The extent of users with multidisciplinary interests, therefore, is important in the determination of organizational structure.

In terms of centralizing scientific and technical libraries, the extent to which these disciplines interact, particularly through the literature, should be examined. Existing knowledge relating to the 
interaction of science and technology is equivocal. Storer observed that "it has been increasingly the case that scientific advances are directly responsible for technological advances (and) it is only because of the increasing dependence of technology on scientific progress and the closer ties between science and the common universe of discourse, that we now speak of the 'practical' importance of science." 19 In contrast, Price, following an analysis of citation patterns in scientific and technical literature, observed that the "interaction between science and technology seems to proceed only slightly and with great difficulty through the literature."20

In an analysis of the communication patterns of engineers in industrial environments, Allen presents an appealing, and apparently valid, explanation of why the average engineer makes little use of research-oriented literature. He stated that "most of the professional engineering literature is too mathematically sophisticated for the average engineer to comprehend. It is therefore inaccessible to him." 21 If the average engineer lacks the mathematical sophistication to interpret the professional engineering literature, in all probability he likewise lacks the ability to interpret the research-oriented literature of science. If this argument were valid for engineers in academic as well as industrial environments, establishing a centralized library would not seem justified.

To study the relationship between the citation of scientific literature and the institutional affiliation of engineers, Waldhart performed a citation analysis of a selected sample of articles written by engineers. ${ }^{22}$ Results of this analysis clearly indicated that, contrary to popular opinion, engineers who publish tend to make extensive use of scientific literature. ${ }^{23}$ The major exception to this generalization was those source articles published in trade journals. These source articles generally lacked references, and were authored by individuals who lacked the Ph.D. degree and possessed industrial affiliations. Trade journals were not generally employed by engineers with academic affiliations either as a citation source or as a publication outlet.

In addition, engineers with academic affiliations were found to be more scientific in orientation (they cited a significantly higher proportion of references from science), and more literature conscious or dependent (they cited a significantly higher number of references per source article), than engineers with nonacademic affiliations. ${ }^{24}$

Although Waldhart studied only the engineer's use of scientific literature, the extent to which scientists cross over and make use of technological literature is generally felt to be considerably less, although no recent study of this subject exists. ${ }^{25}$ More likely, crossover by scientists occurs primarily within the structure of science itself, rather than between science and technology. Some changes in the scientist's use of technological literature can be expected with the recent modification of funding policies of the federal government which tend to emphasize applied as contrasted with basic research, and the growth of multidisciplinary research institutes devoted to the study of environmental problems. ${ }^{26}$

Thus from the point of view of the engineer in academic environments, it would appear that engineers could benefit from the improved accessibility to scientific literature which would result from a centralization of scientific and technical libraries. However, it should be emphasized that the reorganization of university library systems should not be based solely upon such evidence. It represents only a "bit" of information which may be useful for understanding the complexity of any decision to centralize or decentralize scientific and technical libraries. 


\section{Conclusions}

The Association of Research Libraries stated that "librarians indicate that little data are available to assist them in making such decisions (centralization or decentralization)."27 In this light, two basic conclusions seem inescapable: first, because of the uniqueness of local circumstances it is unlikely that a "general theory" of library organization, which can guide the decision-making process, will be formulated in the near future; second, if librarians need data to support the decision-making process, it will fall to them to generate such data.

Decisions relative to the organizational patterns which university library systems will assume in the future can be made on a "crisis" basis, where decisions are forced, often prematurely, by immediate problems which require solu- tion; or, they may be made on the basis of careful, long-range planning which attempts to deal "systematically with future opportunities, problems and alternative courses of action." 28 It seems patently apparent that the second course of action is preferable. Implicit in this course is the need for more intensive and extensive research related to the relationship between organizational patterns of libraries and their performance. This paper identified three areas felt to be particularly deserving of attention-many more could be detailed. The library community, both practitioners and those primarily concerned with research, must take the initiative in conducting such studies. Failure to accept this challenge can only lead to a further degrading of the role of librarians as active participants in university decision making.

\section{REFERENCES}

1. Booz, Allen \& Hamilton, Inc., Problems in University Library Management (Washington, D.C.: Association of Research Libraries, 1970), p. 35 .

2. Arthur M. McAnally and Robert B. Downs, "The Changing Role of Directors of University Libraries," CRL 34:103-25 (March 1973).

3. Marianne Cooper, "Organizational Patterns of Academic Science Libraries," CRL 29: 357-63 (Sept. 1968); Lawrence Thompson, "The Historical Background of Departmental Collegiate Libraries," Library Quarterly 12:49-74 (Jan. 1942); D. A. Wells, "Individual Departmental Libraries vs. Consolidated Science Libraries," Physics Today 14:40-41 (May 1961); J. H. Shera, "How Much Is a Physicist's Inertia Worth?" Physics Today 14:42-43 (Aug. 1961); Harvey Marron, "Science Libraries: Consolidated or Departmental?" Physics Today 16:34-39 (July 1963); Jean Legg, "Death of the Departmental Library," Library Resources and Technical Services 9:351-55 (Summer 1965); Robert R. Walsh, "Branch Library Planning in Universities," Library Trends 18:210-22 (Oct. 1969); Michael J. Bruno, "Decentralization in Aca- demic Libraries," Library Trends 19:31117 (Jan. 1971).

4. G. Edward Evans and Harold Borko, Effectiveness Criteria for Medical Libraries: Final Report (Institute of Library Research, University of California, Los Angeles, April 1970, ED 057 813).

5. F. W. Lancaster, "The Cost-Effectiveness Analysis of Information Retrieval and Dissemination Systems," American Society for Information Science Journal 22:12-27 (Jan.-Feb. 1971).

6. Phyllis Richmond, "Systems Evaluation by Comparison Testing," CRL 27:23-30 (Jan. 1966).

7. Nicholas J. Demerath, et al., Power, Presidents, and Professors (New York: Basic Books, 1967).

8. McAnally, "Changing Role of Directors."

9. Guy R. Lyle, The Librarian Speaking: Interviews with University Librarians (Athens, Ga.: University of Georgia Press, 1970), p.106-13.

10. Rutgers University, Graduate School of Library Service, Studies in Library Service, Studies in Library Administrative Problems (New Brunswick, N.J.: Rutgers University, $1960)$, p.133-56. 
11. The twenty-five largest university libraries were identified through The Bowker Annual of Library and Book Trade Information (New York: Bowker, 1970), p.16-17. Directors of the libraries were identified through The American Library Directory, 1970-1971, 27th ed. (New York: Bowker, 1971). Biographical information for the directors was identified through A Biographical Directory of Librarians in the United States and Canada, 5th ed. (Chicago: American Library Association, 1970).

12. Richard M. Dougherty, "The Evaluation of Campus Library Document Delivery Service," CRL 34:29-39 (Jan. 1973).

13. Thomas J. Allen and Peter G. Gerstberger, Criteria for Selection of an Information Source (Alfred P. Sloan School of Management, M.I.T., Working Paper \#284-67, Sept. 1967, PB 176 899), p.23.

14. Ibid., p.19-20.

15. Jeffrey Raffel and Robert Shishko, "Centralization vs. Decentralization: A Locational Analysis Approach for Librarians," Special Libraries 63:135-43 (March 1972).

16. Allen, Criteria for Selection, p.23.

17. Wells, "Individual Departmental Libraries," p.40-41.

18. Raffel, "Centralization vs. Decentralization," p.142.

19. Norman W. Storer, The Social System of Science (New York: Holt, 1966), p.2.
20. Derek J. de Solla Price, "Is Technology Historically Independent of Science? A Study in Statistical Historiography," Technology and Culture 6:553-68 (Fall 1965).

21. Allen, Criteria for Selection, p.20-21.

22. Thomas J. Waldhart, "The Relationship Between the Citation of Scientific Literature and the Institutional Affiliation of Engineers" (Unpublished Ph.D. dissertation, Indiana University, Jan. 1973).

23. Janice M. Ladendorf, "Information Flow in Science, Technology, and Commerce; A Review of the Concepts of the Sixties," Special Libraries 61:215-22 (May-June 1970); Donald G. Marquis and Thomas J. Allen, "Communication Patterns in Applied Technology," American Psychologist 21: 1052-60 (Nov. 1966); Price, "Is Technology Historically Independent of Science?" p.553-68.

24. Waldhart, "The Relationship," p.174.

25. Herman H. Fussler, "Characteristics of the Research Literature Used by Chemists and Physicists in the United States," Library Quarterly 19:19-35 (Jan. 1949).

26. Mina Rees, "The Saga of American Universities: The Role of Science," Science 179: 19-23 (5 Jan. 1973).

27. Booz, Problems, p. 35 .

28. George A. Steiner, "The Critical Role of Top Management in Long-range Planning," Arizona Review 14:5-13 (April 1966). 